\title{
Cordoba Observations of Comet 1891 I (Barnard-Denning).
}

Owing to cloudy weather, this comet could not be observed until the $17^{\text {th }}$ of June, and it was then so faint in the strong moonlight that, until after full moon, filar micrometer measures could only be obtained with great diffculty. 'These were continued, however, as the weather permitted, until its light had diminished so much that it was lost under the faintest possible illumination of the micrometer threads. June $28^{\text {th }}$, the comet was undistinct from its proximity to an $8^{\text {th }}$ magnitude star. July 6 , clouds after the first observation. Upon the first three dates given below, the observations were made by me; thereafter, by first assistant Richard H. Tucker.

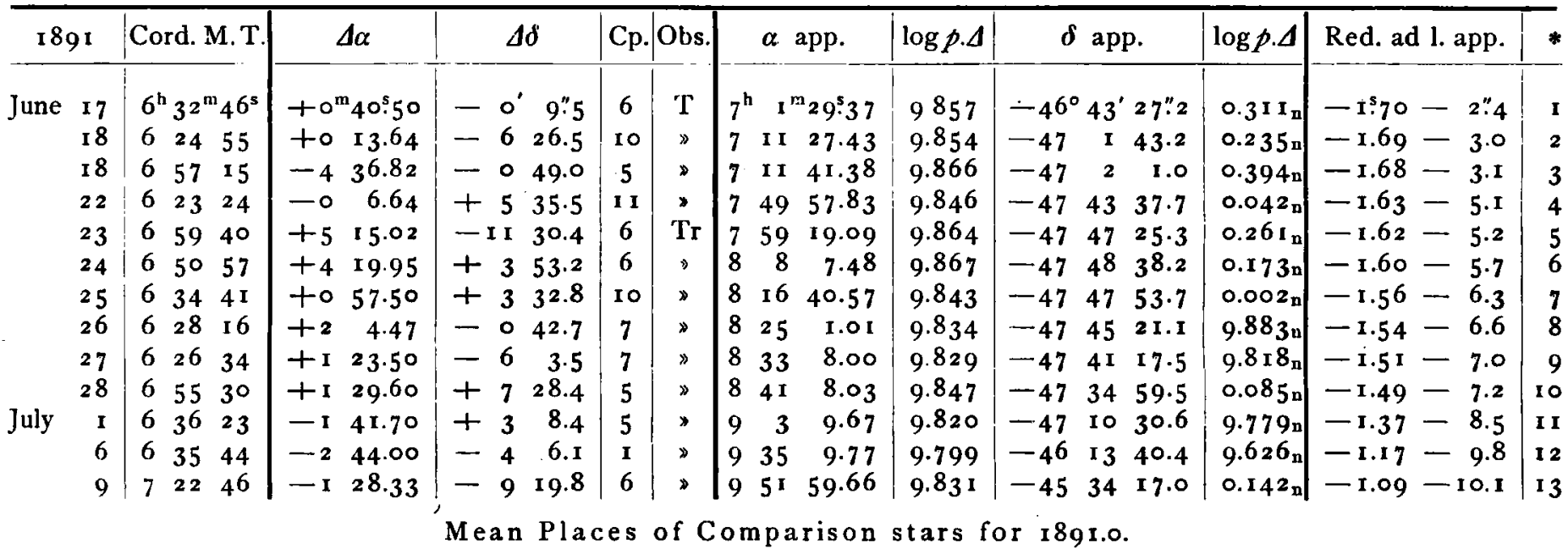

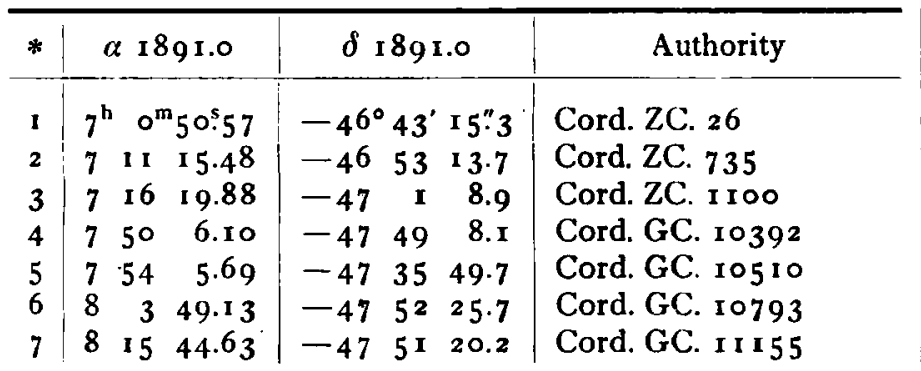

\begin{tabular}{|c|c|c|c|}
\hline$*$ & $\alpha \times 89 \mathrm{r} .0$ & $\delta$ r 89 r.o & Authority \\
\hline 8 & $8^{\mathrm{h}} 22^{\mathrm{m}} 5^{8 \mathrm{~s}} .08$ & $-47^{\circ} 44^{\prime} 31^{\prime \prime} .8$ & Cord. GC. I I $35^{8}$ \\
\hline 9 & 83146.01 & $-4735 \quad 7.0$ & Cord. GC. I I 593 \\
\hline IO & $\begin{array}{lll}8 & 39 & 39.92\end{array}$ & $\begin{array}{lll}-47 & 42 & 20.7\end{array}$ & Cord. GC. 11828 \\
\hline I I & $\begin{array}{lll}9 & 4 & 52.74\end{array}$ & $\begin{array}{lll}-47 & \text { I } 30.5\end{array}$ & Cord. GC. I 246 r \\
\hline 12 & $937 \quad 54.94$ & $--4^{6} \quad 9 \quad 24.5$ & Cord. GC. 13243 \\
\hline$I_{3}$ & 95329.08 & $\begin{array}{llll}-45 & 24 & 47.1\end{array}$ & Cord. ZC. 4073 \\
\hline
\end{tabular}

National Argentine Observatory, Cordoba 189 I July 22.

Fohn M. Thome.

\section{Planet (311) (Charlois 1891 Juni 11).}

Dieser Planet ist von Herrn Charlois an 9 Tagen vom I1. Juni bis 7. August beobachtet worden. Aus drei Oertern, 11. Juni, 6. Juli und 7. August, hat sich folgende sehr kreisähnliche Bahn ergeben:

Epoche 1891 Aug. 7.5 M. Z. Berlin.

Berlin 189 r Sept. I.

$$
\begin{aligned}
& M=128^{\circ} 54^{\prime} 55^{\prime \prime} .4 \\
& w=60 \mathrm{I} 31.6 \\
& \delta=8 \mathrm{1} 36.6 \\
& i=3 \mathrm{1} 6 \mathrm{14.5}
\end{aligned}
$$

M. Aequ. 189 r.o

$$
\varphi=I^{\circ} 18^{\circ} 26^{\prime \prime} \circ
$$$$
\mu=721.972
$$$$
\log a=0.46099 \mathrm{I}
$$

A. Berberich, Hülfsarbeiter am astr. Recheninstitut.

Beobachtung des Planeten (314) (Palisa Aug. 30) auf der Sternwarte in Hamburg.

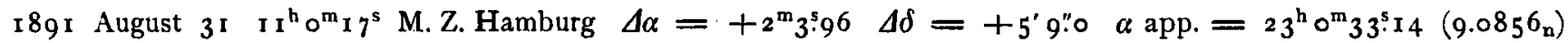
$\delta$ app. $=-\mathrm{I}^{\circ} 34^{\prime} \mathrm{I}^{\prime \prime 2}\left(0.85^{8}\right)$ Red. ad 1. app. $=+2.45+\mathrm{I} 3^{\prime \prime} 8$

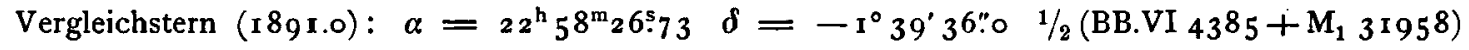
Während der Beobachtung mehrfach Wolken. 